\title{
Ecological succession leads to chemosynthesis in mats colonizing wood in sea water
}

\author{
Dimitri Kalenitchenko ${ }^{1}$, Marlène Dupraz ${ }^{1}$, Nadine Le Bris ${ }^{1}$, Carole Petetin ${ }^{2}$, \\ Christophe Rose ${ }^{3}$, Nyree J West ${ }^{2}$ and Pierre E Galand ${ }^{1}$ \\ ${ }^{1}$ Sorbonne Universités, UPMC Univ Paris 06, CNRS, Laboratoire d'Ecogeochimie des Environnements \\ Benthiques (LECOB), Observatoire Océanologique, Banyuls sur Mer, France; ${ }^{2}$ Sorbonne Universités, UPMC \\ Univ Paris 06, CNRS, Observatoire Océanologique de Banyuls (OOB), Banyuls sur Mer, France and ${ }^{3} U M R$ EEF \\ INRA/UL, Plateforme Technique d'Ecologie et d'Ecophysiologie Forestières (PTEF), INRA-LORRAINE, \\ Champenoux, France
}

\begin{abstract}
Chemosynthetic mats involved in cycling sulfur compounds are often found in hydrothermal vents, cold seeps and whale falls. However, there are only few records of wood fall mats, even though the presence of hydrogen sulfide at the wood surface should create a perfect niche for sulfide-oxidizing bacteria. Here we report the growth of microbial mats on wood incubated under conditions that simulate the Mediterranean deep-sea temperature and darkness. We used amplicon and metagenomic sequencing combined with fluorescence in situ hybridization to test whether a microbial succession occurs during mat formation and whether the wood fall mats present chemosynthetic features. We show that the wood surface was first colonized by sulfide-oxidizing bacteria belonging to the Arcobacter genus after only $\mathbf{3 0}$ days of immersion. Subsequently, the number of sulfate reducers increased and the dominant Arcobacter phylotype changed. The ecological succession was reflected by a change in the metabolic potential of the community from chemolithoheterotrophs to potential chemolithoautotrophs. Our work provides clear evidence for the chemosynthetic nature of wood fall ecosystems and demonstrates the utility to develop experimental incubation in the laboratory to study deep-sea chemosynthetic mats.
\end{abstract}

The ISME Journal (2016) 10, 2246-2258; doi:10.1038/ismej.2016.12; published online 23 February 2016

\section{Introduction}

Wood falls represent an important carbon load for the seabed (Blair and Aller, 2012). They form the foundation for unique deep-sea ecosystems, but, intriguingly, some wood-colonizing organisms do not use directly organic wood carbon. They prefer instead to consume inorganic carbon and use as an energy source compounds such as hydrogen sulfide (Duperron et al., 2008). High hydrogen sulfide concentrations have been measured on wood falls in situ (Laurent et al., 2013) and in aquaria (Yücel et al., 2013) with values similar to the ones measured in hydrothermal vent fluids (Le Bris et al., 2006). The production of hydrogen sulfide has been related to the presence of bacteria from the Desulfovibrio genera, detected after only 1 month of wood immersion (Kalenitchenko et al., 2015), which respire sulfate and use fermentation products like

Correspondence: D Kalenitchenko, Sorbonne Universités, UPMC Univ Paris 06, CNRS, Laboratoire d'Ecogeochimie des Environnements Benthiques (LECOB), Observatoire Océanologique, Avenue du Fontaule, Banyuls sur mer 66650, France.

E-mail: dimitri.kalenitchenko@obs-banyuls.fr

Received 7 August 2015; revised 5 January 2016; accepted 8 January 2016; published online 23 February 2016 acetate as a carbon source. However, after several months of immersion, when all the labile organic matter present in the wood was consumed, it was hypothesized that the microbial community needs a macrofaunal partner (Xylophaga sp.) to convert the refractory wood carbon into labile organic matter (Voight, 2015). New fermentative niches can be created within macrofaunal feces (Purchon, 1941; Fagervold et al., 2014) that could result in high hydrogen sulfide concentration after 1 year (Bienhold et al., 2013). These environmental chemical conditions are similar to the ones found in other deep-sea sulfidic habitats where microbial mats colonize exposed surfaces. Similarly, chemosynthetic microbial mats should be expected to develop on wood surfaces.

Epixylic mats (mats that develop on the surface of the wood) are well studied in freshwater environments and consist of microbial communities dominated by fungi able to degrade lignin and cellulose (Golladay and Sinsabaugh, 1991; Tank and Winterbourn, 1995; Tank and Webster, 1998). In contrast, little is known about epixylic mats in the marine environment. Their presence has been reported only recently in studies from shallow waters or mesocosm experiments (Laurent et al., 2013; Yücel 
et al., 2013; Kalenitchenko et al., 2015) but the identity and function of the mat-forming bacteria are unknown. For deep-sea woods, sampling is difficult because the long distances traveled when moving up through the water column washes the wood, leaving no trace of the fragile biofilm structure (Samadi et al., 2010).

Deep-sea mats have, however, been studied in other chemosynthetic ecosystems such as mud volcanos (Girnth et al., 2011), cold seeps (Grünke et al., 2011; Gentz and Schlüter, 2012) or hydrothermal vents (Taylor et al., 1999; Alain et al., 2004). These studies highlighted the key role played in sulfidic habitats by Epsilonproteobacteria (Campbell et al., 2006) during the establishment of deep-sea chemosynthetic ecosystems. For carbon acquisition some members of this class use the reverse TCA cycle (rTCA) to fix inorganic carbon (Takai et al., 2005; Hügler and Sievert, 2011) and chemosynthetic fauna inhabiting hydrothermal vents probably rely on bacterial carbon (Van Dover and Fry, 1989) and more precisely on carbon fixed using the rTCA cycle (López-García et al., 2003). Epsilonproteobacteria were also described as the first colonizers of new surfaces exposed to the mixing zone surrounding vent chimneys (Alain et al., 2004; Heijs et al., 2005) validating their key role in deep-sea sulfidic environments. However, other bacterial groups are important and three main kinds of sulfidic chemosynthetic mats have been described. Thiomargarita (Gammaproteobacteria) mats develop within highly dynamic habitats where hydrogen sulfide and oxygen (or nitrate) gradients are unstable (Girnth et al., 2011). Arcobacter (Epsilonproteobacteria) mats develop in niches where hydrogen sulfide and oxygen co-occur (Wirsen et al., 2002; Moussard et al., 2006; Grünke et al., 2011). Finally, Beggiatoa (Gammaproteobacteria) mats reduce the narrow overlap region between hydrogen sulfide and oxygen (or nitrate) and promote a steep gradient within the mat (Felden, 2009). Owing to the difficulty of accessing deep-sea samples, these mat categories present only a snapshot of the mat communities at a given time and the possible ecological succession of the microbial community composition remains unexplored.

During the formation of microbial mats, bacteria change their lifestyle from a free-living stage to a multicellular community by secreting extracellular polymeric substances that can represent $90 \%$ of a mat volume (Flemming and Wingender, 2010). Mat establishment strongly affects chemical gradients between the water and the substrate (Santegoeds et al., 1998) and consequently can create new ecological niches. In wood falls, we suspect that changing chemical conditions measured on the wood surface (Yücel et al., 2013) may result in a surface community adapted to changes in sulfide concentrations, similar to community changes observed in deep-sea chemosynthetic ecosystems (Alain et al., 2004). We hypothesize that mat development on wood creates with time new niches that might be colonized by specific bacterial groups.
Furthermore, wood is composed mostly of polysaccharides (Sjostrom, 1993) so the microbial mat may use polysaccharides directly from the wood surface as observed in freshwater fungal biofilms (Golladay and Sinsabaugh, 1991).

In the present study we aim to fill the knowledge gaps in the least studied of the four deep-sea chemosynthetic ecosystems, wood falls. The overarching goal of this study is to provide a first description of a wood fall microbial mat and to verify if the mat bacterial community changes with time. We used a mesocosm experiment, which we developed to mimic deep-sea conditions (Kalenitchenko et al., 2015), to overcome the difficulty of repeatedly recovering fragile wood fall mats from the deep ocean. We combined illumina amplicon sequencing, metagenomics, fluorescence in situ hybridization (FISH), microsensor profiles, elemental mapping and image monitoring to investigate the diversity and function of the microbial community. This experiment allowed us to test (i) whether a microbial succession occurs during mat formation and (ii) whether the wood fall biofilms present chemosynthetic features.

\section{Materials and methods}

\section{Experimental set up}

Five wood logs $(15 \mathrm{~cm}$ in diameter and $10 \mathrm{~cm}$ in length) were placed in aquaria filled with $5 \mu \mathrm{m}$-filtered seawater pumped (flow: $8 \mathrm{lh}^{-1}$ ) from the Mediterranean Sea at $4 \mathrm{~m}$ depth, $30 \mathrm{~m}$ away from shore. Seawater temperature was maintained at $13 \pm 1{ }^{\circ} \mathrm{C}$ and oxygen concentrations were maintained at $100 \%$ saturation by bubbling. Wood logs originated from a same pine tree (Pinus pinea) cut the day before the start of the experiment in the Banyuls sur Mer 'Biodiversarium' botanical garden. Pictures of each of the five wood logs were taken every day to monitor the color, the thickness and the area covered by the mats developing on the wood surface.

\section{Sampling, fixation and filtration}

Wood mats were sampled after 32, 35, 38, 43, 45 and 49 days of wood immersion. For each sampling time, mats were sampled with a punch $(4.35 \mathrm{~mm}$ in diameter) from wood logs chosen randomly (Supplementary Table 1). Samples were always taken $>50 \mathrm{~mm}$ away from an earlier sampling site to avoid any 'earlier sampling site' effect. One catalyzed reporter deposition-FISH (CARD-FISH) sample and two DNA samples were collected at each time point. For DNA analysis, samples were stored in $2 \mathrm{ml}$ cryotubes at $-80^{\circ} \mathrm{C}$. For CARD-FISH, samples were suspended and fixed with $1 \mathrm{ml}$ of paraformaldehyde solution diluted to $4 \%$ with phosphate-buffered saline (PBS) for $6 \mathrm{~h}$ at $4{ }^{\circ} \mathrm{C}$. Then $50 \mu \mathrm{l}$ of this solution was filtered onto a $25-\mathrm{mm}$ diameter filter (Whatman, Nuclepore $0.2 \mu \mathrm{m}$ ), the filters rinsed three times with a $1 \times$ PBS solution and then stored at $-20^{\circ} \mathrm{C}$. 
CARD-FISH

CARD-FISH was performed according to a previously published protocol (Pernthaler et al., 2002). Nuclepore filters with mat cells were embedded in $0.1 \%$ low gelling point agarose. Cells on the embedded filters were permeabilised with lysozyme buffer (10 mg ml-1 of Lysozyme (105 $000 \mathrm{U} \mathrm{mg}^{-1}$, SIGMA, Saint Louis, MO, USA) in $0.05 \mathrm{~m}$ ethylenediaminetetraacetic acid, $0.1 \mathrm{~m}$ Tris- $\mathrm{HCl}(\mathrm{pH}$ 8.0) and endogenous peroxidases inactivated by treatment with $0.01 \mathrm{M} \mathrm{HCl}$. Filters were cut into six equal parts and four parts were incubated with the following probes; a Bacteria probe (EUB338-I) (Amann et al 1990), a negative control probe (NON338), which is the reverse complement of the universal probe, an Epsilonproteobacteria class probe (EPSY549 (Lin et al., 2006)), and a Gammaproteobacteria class probe (GAM42a (Manz et al., 1992)). Because GAM42a may also target some Betaproteobacteria we used the unlabeled BET42a probe (Manz et al., 1992) as a competitor probe. Filter fragments were covered with hybridization buffer $(0.9 \mathrm{M} \mathrm{NaCl}, 20 \mathrm{~mm}$ Tris-HCl, $\mathrm{pH}$ 8.0), $10 \%$ dextran sulfate, $0.02 \%$ sodium dodecyl sulfate, $55 \%$ formamide (Sigma) and 1\% Blocking Reagent (Roche, Basel, Switzerland) containing the probe at $2.5 \mathrm{ng}^{-1}$, and incubated in a hybridization chamber prepared with $55 \%$ formamide solution during $3 \mathrm{~h}$ at $35^{\circ} \mathrm{C}$. Filters were washed in washing buffer $(5 \mathrm{~mm}$ ethylenediaminetetraacetic acid $\mathrm{pH} 8$ ), $20 \mathrm{~mm}$ Tris-HCl (pH 8), $0.01 \%(\mathrm{w} / \mathrm{v})$ sodium dodecyl sulfate and $13 \mathrm{~mm}$ $\mathrm{NaCl}$ ) for $10 \mathrm{~min}$ at $37^{\circ} \mathrm{C}$ and the equilibriated in $1 \times$ PBS for 15 min at room temperature. Filters were covered with the CARD substrate mix and incubated for $30 \mathrm{~min}$ at $37^{\circ} \mathrm{C}$ in the dark. The CARD substrate was prepared by mixing the amplification buffer (10\% dextran sulfate, $2 \mathrm{M} \mathrm{NaCl}, 0.1 \%(\mathrm{w} / \mathrm{v})$ blocking reagent, in $1 \times$ PBS ( $\mathrm{pH}$ 7.6) and $\mathrm{H}_{2} \mathrm{O}_{2}$ solution (0.15\% in PBS) at a 1:100 ratio) with the substrate fluorescein tyramide (Perkin Elmer, Waltham, MA, USA) at a ratio of 1 part tyramide to 200 parts amplification buffer. Filters were mounted on slides using a mounting mix (Citifluor and Vectashield at a 4:1 ratio and 4',6-diamidino-2-phenylindole (DAPI) at $0.5 \mu \mathrm{g} \mathrm{ml}^{-1}$ ). Observations and counts were achieved with a BX61 microscope (Olympus, Tokyo, Japan) equipped with FITC (U-N41001 HQIF) and DAPI (U-MNU2) filter sets. For each sampling time and each probe, 12 fields of view were counted for the CARD-FISH-labeled bacteria and DAPI-labeled cells and the relative abundance of labeled cells expressed as a \% of the DAPI-labeled cells.

DNA extraction, illumina amplicon and metagenome sequencing

Frozen samples were thawed on ice, centrifuged for $30 \mathrm{~s}$ at $6000 \mathrm{rpm}$ and supernatants were discarded. DNA extraction was performed using the 'PowerPlant DNA isolation kit' (MOBIO Laboratories, Carlsbad, CA, USA). Purified DNA was suspended in $50 \mu \mathrm{l}$ of Tris-ethylenediaminetetraacetic acid buffer.

For amplicon sequencing, a portion of the $16 \mathrm{~S}$ ribosomal RNA (rRNA) gene was amplified using the bacteria-specific primers $28 \mathrm{~F}$ (5'-TTTGATCNTGGC TCAG- $3^{\prime}$ ) and $519 \mathrm{R}$ (5'-GTNTTACNG CGGCKGCT G-3'). DNA samples were sequenced on a Miseq Illumina sequencer (Illumina, San Diego, CA, USA) using Miseq reagent kit V3 (Illumina) producing $2 \times 300$-bp long reads in a commercial laboratory (MR DNA, Lubbock, TX, USA).

For metagenomes, a double-sequencing strategy was adopted to get a combination of high coverage. One sample per time point was sequenced first on a Miseq Illumina sequencer (Illumina) using the Miseq reagent kit V3 (Illumina) to get longer reads $(2 \times 300 \mathrm{bp})$ and then on a Hiseq Illumina sequencer (Illumina) $(2 \times 150 \mathrm{bp})$ to get a larger number of reads. Metagenome sequencing was conducted by a commercial laboratory (MR DNA) using commercially prepared reagents.

\section{Sequence data analysis}

$16 \mathrm{~S}$ rRNA sequences were processed following the standard operating procedure in Mothur (Kozich et al., 2013). In brief, sequences were paired, producing ca. $500 \mathrm{bp}$ fragments. Sequences were then quality trimmed and chimeras were removed using UCHIME (Edgar et al., 2011). Sequences were grouped in operational taxonomic units (OTU) if they were $>97 \%$ similar. The taxonomy of the most abundant sequence of each OTU was assigned using the SILVA SSU 119 database (Pruesse et al., 2007). All samples were resampled down to 5131 sequences per sample. Three sample duplicates (d32, d45 and d49) were removed from further analysis because the amplification was not successful. Sequences were deposited in NCBI SRA under accession numbers SRP061945

Metagenome sequences from Miseq and Hiseq sequencing were concatenated into two files, one forward (containing Miseq and Hiseq forward reads) and one reverse (containing Miseq and Hiseq reverse reads). Miseq sequences are longer, which improves gene assignation, whereas Hiseq sequences are short but in high abundance, which increases the coverage of the community gene diversity. The combination of these two sequencing methods maximized our chance to get a precise and deep coverage of the communities. Forward and reverse reads were joined with a minimum overlap of $8 \mathrm{bp}$ and a maximum difference of $10 \%$. Both paired and unpaired reads were retained for further analysis. Low-quality region trimming (phred score $\leqslant 15$ ) was done with SolexaQA (Cox et al., 2010). Sequences that passed the quality trimming were dereplicated using a k-mer approach that identified sequences that contain identical 20-character prefix. Artificial duplicated sequences were removed (Gomez-Alvarez et al., 2009) and then a machine learning-based approach, 
FragGeneScan (Rho et al., 2010) identified openreading frames, which were annotated by BLASTX (Camacho et al., 2009) against the KEGG (Kanehisa, 2002) and SILVA (Pruesse et al., 2007) databases. Analyses were conducted with the MG-RAST pipeline (Meyer et al., 2008) and sequences were deposited under the accession numbers 4623131.3, 4623132.3 and 4623133.3.

To compare the metabolic potential between communities each data set was resampled down to 20341628 sequences to avoid any sample size effect. Then we counted the number of sequences related to functional genes present in the KEGG database (Kanehisa, 2002) linked with aerobic respiration, carbon cycle (aerobic and anaerobic carbon fixation, carbon monoxide oxidation, fermentation, sulfur cycle (sulfur mineralization, sulfur oxidation and dissimilatory sulfate reduction), nitrate cycle (Nitrate reduction) and methane cycle (methane production and consumption) (Supplementary Table 2). Gene selection and categorization was done according to previous publications (Lauro et al., 2011; LlorensMarès et al., 2015). We also looked at polysaccharide degradation genes that include cellulosome and starch sequestration systems. For proteins encoded by two or more subunits, we used the mean of the sequence abundance in the subunits.

\section{Computation of microbial diversity and function}

Comparison of bacterial community composition between different sampling times was achieved using a non-metric multidimensional scaling based on a Bray-Curtis dissimilarity matrix. The matrix was calculated on a resampled data set that contained only abundant OTUs. An abundant OTU within a sample was defined as an OTU that encompassed $>1 \%$ of the sequences.

The resampled data set was also used to plot the relative bacterial class abundance over time for comparison with the CARD-FISH counts. An analysis of variance was conducted on the replicate CARD-FISH counts to test if the abundance of the different bacterial class varied significantly with time. The analysis of variance prerequisite (normality, independence and homoscedasticity) were verified.

We constructed ternary diagrams with ggtern (v1.0.3.1) to compare functional gene and OTU abundance between samples. All statistics were computed with the R software (V 2.15.13, Vienna, Austria).

\section{Additional microsensors measurements and mat surface elemental analysis}

A similar experiment using exactly the same incubation protocol for the wood logs was launched to investigate the chemical characteristics of the wood mat. Chemical profiles were obtained after 40 days with Ox100 and H2S100 amperometric microsensors (Unisense, Aarhus, Denmark) and a $\mathrm{pH}$ minielectrode. Electrode tips were inserted into the mat using a micromanipulator (Unisense), with depth intervals of $0.25 \mathrm{~mm}$. Sulfide and $\mathrm{pH}$ electrodes were calibrated at $13^{\circ} \mathrm{C}$ in the laboratory, by standard additions of respectively, sodium sulfide stock solution $(284 \mathrm{~mm})$ or HCl $(0.1 \mathrm{M})$ in aquarium seawater. The total sulfide concentration was calculated from the sulfide measured by the electrode using the apparent acidity constants defined by Rickart and Luther. (2007).

In addition, to validate the presence of sulfur on the wood mat surface, a piece of the 40-day-old mat was vitrified on cold isopentane $\left(-150^{\circ} \mathrm{C}\right)$. The vitrified mat was then placed side up on a field emission gun scanning electron microscope (ZEISS Sigma HD, Oberkochen, Germany) under secondary vacuum and maintained at a temperature of $-130^{\circ} \mathrm{C}$ on a cryogenic stage (VCT 100 Leica, Wetzlar, Germany) during electron beam scanning (15 KV) at a working distance of $10 \mathrm{~mm}$. Mat surface images were obtained using a secondary electrons detector. Elemental mapping of microstructure were achieved by the mapping (100s) of the mat surface with an energy dispersive X-ray spectrometer (Silicon Drift Detector-Xmax ${ }^{\mathrm{N}}-80 \mathrm{~mm}^{2}$, Oxford instruments, Abington, United Kingdom). The raw data was treated with the INCA Energy software (Oxford instruments) to produce a composite image of the scanning microscopy image and sulfur X-ray signature detected by the spectrometer.

\section{Results}

Mat growth

During the first 20 days of immersion the surfaces of the five pieces of wood (Figure 1) showed no apparent colonization. The first traces of mats appeared after 20 days and the mats colonized the entire wood surface within 10 days after their appearance. After 30 days of immersion the mat surface was not homogeneous and showed both white dots and transparent areas (Figure 1). Our study focused on the first stage of mat formation (3249 days after immersion). During this period the mat thickness increased from ca. $1 \mathrm{~mm}$ to $>4 \pm 2 \mathrm{~mm}$. The pattern of mat development was similar on the five replicate pieces of wood (Supplementary Figure 1) and on the wood used for the chemical measurements (Figure 5a).

\section{Bacterial community dynamics}

Miseq illumina sequencing produced 161201 raw $16 \mathrm{~S}$ rRNA paired end reads. After pairing, quality filtering and chimera checking 100426 sequences remained, which clustered into 40 OTUs at $97 \%$ similarity.

Non-metric multidimensional scaling based on a Bray-Curtis distance matrix separated the samples according to time of immersion. The non-metric multidimensional scaling stress value was 0.057 , 
indicating a good ordination of the data. Samples from the beginning of the experiment (d32 to d43) were associated to a group of seventeen OTUs (Figure 2). These OTUs belonged to the order Gammaproteobacteria (Otu 10-11-12-21-22-23-2426-30-31-38), Epsilonproteobacteria (Otu1-2-6-8-42) and Flavobacteria (Otu13). Communities originating from samples incubated for a longer time (d45 and d49) were highly discriminated by axis 1 and were associated to OTUs from the class Deltaproteobacteria (Otu3-9-19-32) and Deferribacteres (Otu 16).

We then observed the dynamics of each of these bacterial classes along time (Figure 3a). Gammaproteobacteria sequence abundance did not vary with time $(11 \% \pm 3 \%)$, but the proportion of Epsilonproteobacteria sequences decreased after 38 days (66\%) and reached a minimum after 49 days $(30 \%)$. The Deltaproteobacteria sequence abundance was a mirror image of that of the Epsilonproteobacteria and remained below $11 \%$ between day 32 and day 38 , and became the dominant class after 49 days $(50 \%)$. Some bacterial classes were detected only at

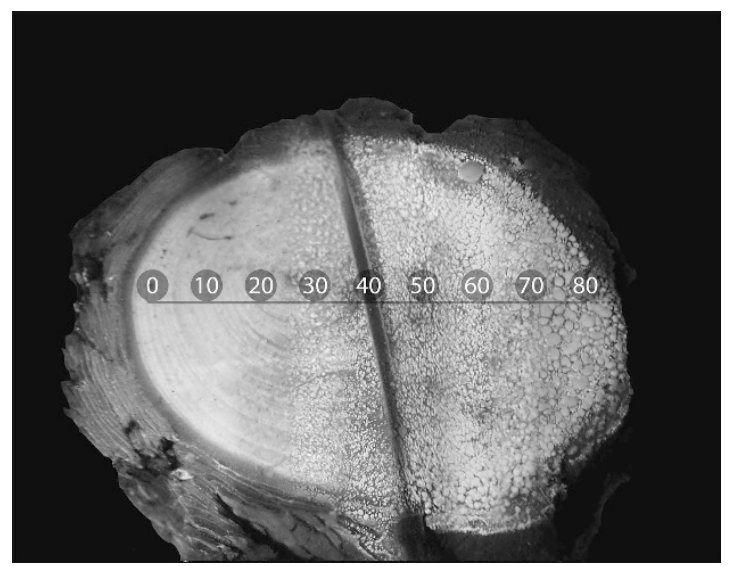

Figure 1 Composite picture showing the growth of a bacterial mat on the surface of a piece of wood immerged in seawater. Numbers indicate days of immersion. The data presented in this paper are from samples taken between 30 and 50 days of immersion. the end of the experiment like the Deferribacteres that were not detected before 38 days and increased in abundance $(>1 \%$ of the total number of sequences) after 49 days (3\%). Replicate samples (d35, d38 and d43) showed similar patterns reflecting a homogenous community composition in the mats.

The dynamics based on high-throughput sequencing results could be biased by the PCR amplification step. Based on the sequencing results we targeted two bacterial classes to validate the temporal dynamics with CARD-FISH. We targeted the Epsilonproteobacteria, as a class that showed variations in abundance, and the Gammaproteobacteria was selected as a stable class. Cell counts were expressed as percentage of labeled cells relative to DAPIstained cells. The CARD-FISH results showed patterns similar to the sequencing results (Figure $3 \mathrm{~b}$ ). Epsilonproteobacteria abundance decreased significantly with time (analysis of variance, $N=54$, $F=69.885, \quad P$-value $=3.453 \mathrm{e}-11)$ from $82 \%$ of the DAPI-stained cells $( \pm 12 \%)$ after 32 days, to $67 \%$ $( \pm 13 \%)$ after 38 days and $40 \%( \pm 15 \%)$ at the end of the experiment. The abundance of Gammaproteobacteria remained close to $8 \%( \pm 5 \%)$ of the DAPIstained cells and did not present any significant variations.

\section{Bacterial community composition}

From the temporal dynamics results we defined three key time points in the development of the mat: d32 (abundant Epsilonproteobacteria), d45 (equally abundant Epsilonproteobacteria and Deltaproteobacteria) and d49 (abundant Deltaproteobacteria), and observed at the OTU level how relative abundances changed between these three time points (Figure 4a).

At the class level, Gammaproteobacteria abundance did not change with time but at the OTU level there were variations. After 32 days, Gammaproteobacteria contained many different equally abundant OTUs, but as time passed, only a few abundant OTUs

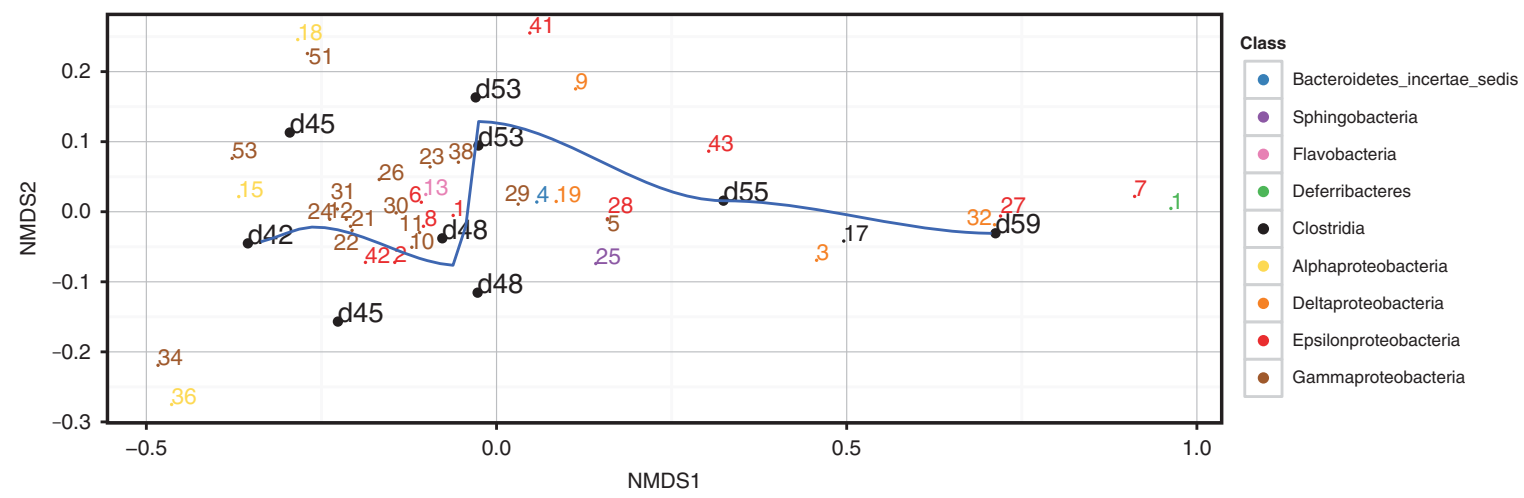

Figure 2 Non-metric multidimensional scaling plot showing changes in bacterial community composition with time. Black dots represent sample names and OTUs were plotted within the NMDS space and colored according to their phylum affiliation. Stress value $=0.057$. 
a

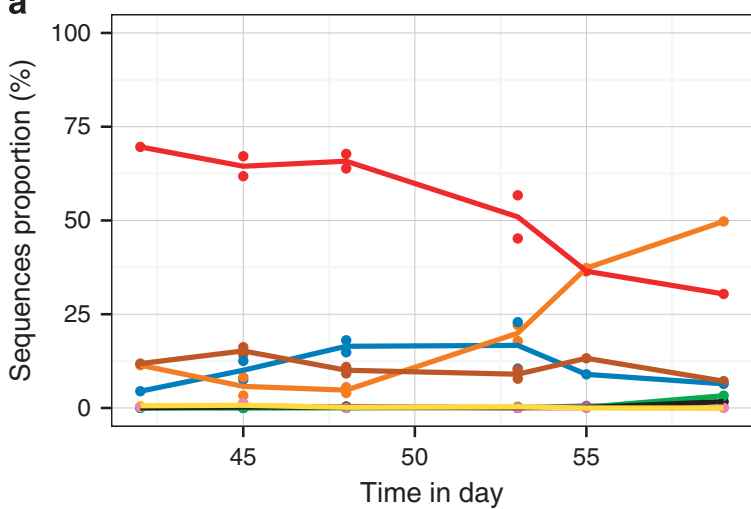

Class

b

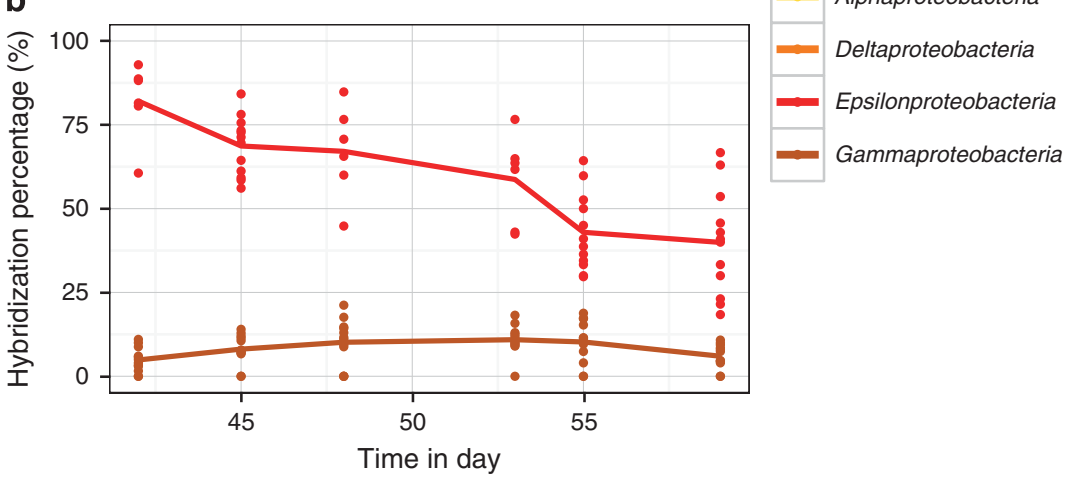

Figure 3 Proportion of bacterial classes in the wood fall mats at different times of immersion. Bacteria were quantified based on the number of $16 \mathrm{~S}$ rRNA sequences (a) and by CARD-FISH cell counts (b). The points in the CARD-FISH figure represent the different microscopic field counted for each sample. The curves were fitted to the mean values when replicates were present.

a

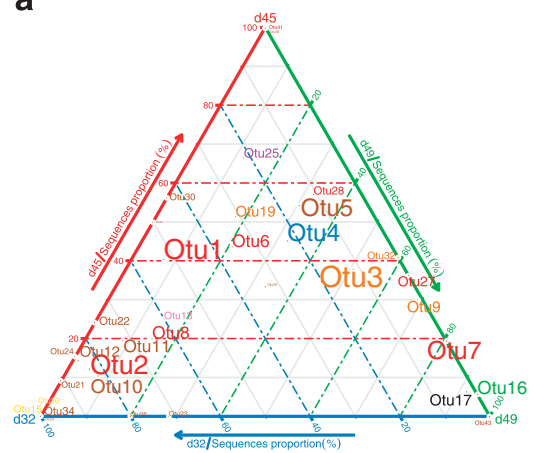

Sequences abundance

- 40

a 400

a 4000

Class

- Bacteroidetesincertae sedis

Sphingobacteria

Flavobacteria

Deferribactere

Clostridia

Alphaproteobacteria

Deltaproteobacteria

Epsilonproteobacteria

Gammaproteobacteria b

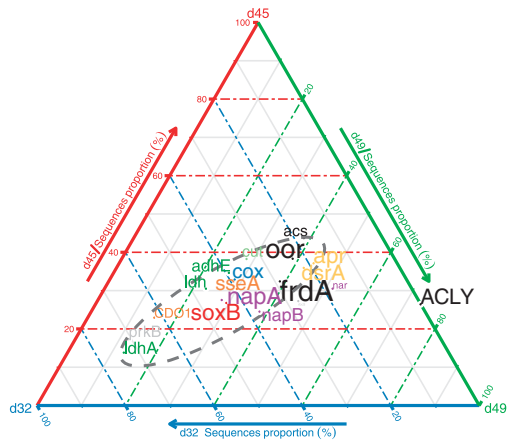

Sequences abundance

- 25

250

2500

a 25000

Metabolism

Aerobic_respiration

Aerobic_C_fix

CO_oxidation

Fermentation

Anaerobic_C_fix

Sulfur_Mineralization

Dissimilatory_sulfate_reduction

Sulfur_oxidation

Nitrate reduction

Figure 4 Triplots representing OTU (a) and functional gene (b) proportions within three normalized samples. The blue axis represents the proportion of sequences after 32 days of immersion (d32), the red axis the proportion after 45 days (d45) and the green axis after 49 days (d49). OTU colors represent the different bacterial classes and gene colors show the different metabolic pathways. OTU and gene name sizes are proportional to the relative abundance of each gene or OTU out of the entire data set.

dominated the class (Figure 4a, Supplementary Figure 2). At the beginning, the Gammaproteobacteria community was dominated by Otu 10-11-12, but then, after 45 days, sequences belonging to these OTUs decreased and the Otu5 became dominant during the rest of the experiment. Otu 10, 11 and 12 were similar to NCBI deposited sequences NR_042965.1 (100\% similarity), NR_029031.1 (100\% similarity) and KC476293.1 (99\% similarity), respectively. These three OTUs belonging to the Oceanospirillaceae family were attributed to the
Marinomonas genus for Otu 10 and 11 and to the Thalassolituus genus for Otu12. Otu5 was distantly related to any known strains ( $<94 \%$ similarity) but a similar sequence was previously found $(100 \%$ similarity to GQ455175.1) in mats from coral black band disease (Ben-Dov et al., 2011).

For the Epsilonproteobacteria, there was a clear succession of the dominant OTUs with time, beginning with Otu2 and Otu1 at d32. Otu1 persisted and dominated at $\mathrm{d} 45$, but was replaced by Otu7 at $\mathrm{d} 49$. Otu1 and Otu2 were not related to any known strains 
( $\leqslant 94$ or $\leqslant 95 \%$, respectively), whereas Otu7 was 95\% similar to Candidatus Arcobacter (Wirsen et al., 2002).

Deltaproteobacteria OTUs were most abundant at the later time points $\mathrm{d} 45$ and $\mathrm{d} 49$ and were dominated by Otu3 ( $>96 \%$ of the Deltaproteobacteria). This OTU sequence was $100 \%$ similar to a sequence from cold seeps (AM404369.1), and 99\% similar to a sequence identified as a Desulfovibrio frigidus strain (NR_043580.1) (Vandieken, 2006) that uses sulfate and sulfite as electron acceptor and thus produces hydrogen sulfide as end product.

Other bacterial classes were represented by one Otu only: Bacteroidetes incertae sedis (Otu4), Sphingobacteria (Otu25), Flavobacteria (Otu13), Deferribacteres (Otu 16) and Clostridia (Otu17). Otu13 was typical for the beginning of the experiment (d32) and was $98 \%$ similar to a sequence identified as Winogradskyella sp. (JX174421.1). Otu25 showed an increased abundance at 45 days and was only distantly related to database sequences $(<94 \%)$. Otu 16 and Otu17 were more abundant at the end of the experiment (d49) and were only 92 and 95\% similar to NCBI database sequences. Otu4 showed only small variations in abundance at the different time points and was also distantly related to any deposited sequences $(<95 \%)$.

\section{Functional gene diversity}

We constructed a metagenome for each of the key time points (d32, d45 and d49), which contained 20341628,21322937 and 20555592 sequences, respectively. A total of $64.5 \% \pm 4 \%$ of the sequences passed the quality-checking step and $49 \% \pm 3.4 \%$ were assigned to known proteins.

Overall, functional genes were less dispersed among samples than OTUs (Figure 4b). All the microbial communities that formed the wood fall mats had the potential for aerobic respiration, aerobic carbon fixation, carbon monoxide oxidation, fermentation, sulfur mineralization, dissimilatory sulfate reduction, sulfur oxidation and nitrate reduction based on the detection of marker genes for these metabolisms in the three metagenomes (Figure 4b). We did not detect any genes linked with methane production or oxidation (mcr or methane monooxygenase). Even though many functional genes were present in all metagenomes, some gene abundances changed with time. Most of the genes were included within a stretched ellipse that went from the sample d32 corner to a middle point situated between sample d45 and d49 (Figure 3b). This shape reflects three main groups of genes: first, genes that were detected in the three samples (close to the triplot centroid), second, genes that were detected mostly in sample d32 (close to the d32 side of the ellipse) and third, genes that were detected in both $\mathrm{d} 45$ and $\mathrm{d} 49$ in nearly equal proportions (close to the $50 \%$ value of the d49 axis).

Fermentation genes, especially the K-lactate dehydrogenase gene $(\operatorname{ld} h A)$ were essentially detected within sample d32, which contained $74 \%$ of the IdhA genes detected. Other fermentation genes (ldh and $a d h E$ ) were less influenced by time (Figure $3 \mathrm{~b}$ ). Phosphoribulokinase gene (prkB), a key enzyme of the Calvin cycle, was more abundant (310 sequences) in the d32 sample compared with the d45 and d49 samples (76 and 53 sequences, respectively). Another gene marker for aerobic carbon fixation, the ribulose-bisphosphate carboxylase small chain gene $(r b c S)$, was rarely detected in our mats (3-5 sequences depending on the sample). Sulfur mineralization marker genes, cysteine dioxygenase (CDO1) and thiosulfate/3-mercaptopyruvate sulfurtransferase (sse $A$ ), were more abundant at d32 (62\% of the CDO1 and $40 \%$ of the sseA genes) than at $\mathrm{d} 45$ and $\mathrm{d} 49$. The sulfur oxidation protein gene $($ sox $B)$ was also more present in the d32 sample $(44 \%$ of the $S_{0 x B}$ ) than after 45 and 49 days (27 and 29\% of the $\operatorname{Sox} B$, respectively). The marker genes for nitrate reduction, cytochrome c-type protein (napB), periplasmic nitrate reductase (napA) and nitrate reductase (nar), were not clearly associated to any sample, reflecting a conserved function during the mat development. The same pattern was observed for the cytochrome c-oxidase (cox) and carbon monoxide dehydrogenase (cut) genes that did not show any temporal dynamics. Anaerobic carbonfixation marker genes were more abundant in the d45 and d49 samples. The ATP citrate lyase gene $(A C L Y)$, involved in the rTCA cycle, fell outside the ellipse and was only detected after 45 (26\% of the ACLY genes) and 49 days (74\% of the ACLY genes). Other anaerobic carbon-fixation genes, the fumarate reductase flavoprotein subunit ( $\operatorname{rd} A$ ), the 2oxoglutarate ferredoxin oxidoreductase (oor) and the acetyl-CoA decarbonylase/synthase (acs), were closer to the triplot centroid than the ACLY gene, but closer to the $\mathrm{d} 45$ and the $\mathrm{d} 49$ samples than to the $\mathrm{d} 32$ sample. The two dissimilatory sulfate reduction genes, sulfite reductase $(d s r A)$ and adenylylsulfate reductase (apr), were affiliated to the Deltaproteobacteria class in the KEGG taxonomy database, validating their affiliation to the dissimilatory sulfate reduction metabolisms. They were both detected more often in the $\mathrm{d} 49$ (42\% of the $d s r A$ and $44 \%$ of the apr genes) and $\mathrm{d} 45$ sample (36\% of the $d s r A$ and $37 \%$ of the apr) than in the d32 sample.

Polysaccharide degradation gene screening (Supplementary Figure 3) did not reveal cellulosome related genes such as the sca cluster genes (encoding the cellulosomal structural proteins, scaffoldins) as observed in the rumen gut (Flint et al., 2008). However, we did detect Sus cluster genes coding for the starch sequestration system found in Bacteroidetes (Flint et al., 2008).

\section{Sulfur detection and chemical gradients on the wood} mat

The second incubation experiment followed the same macroscopic mat development pattern ending 

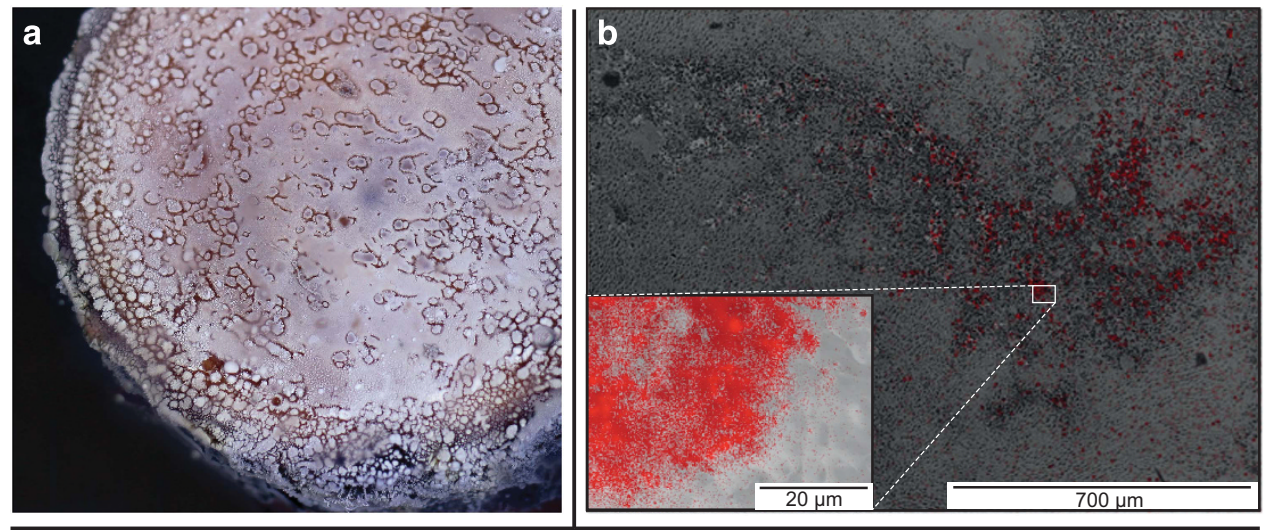

$\mathrm{pH}$

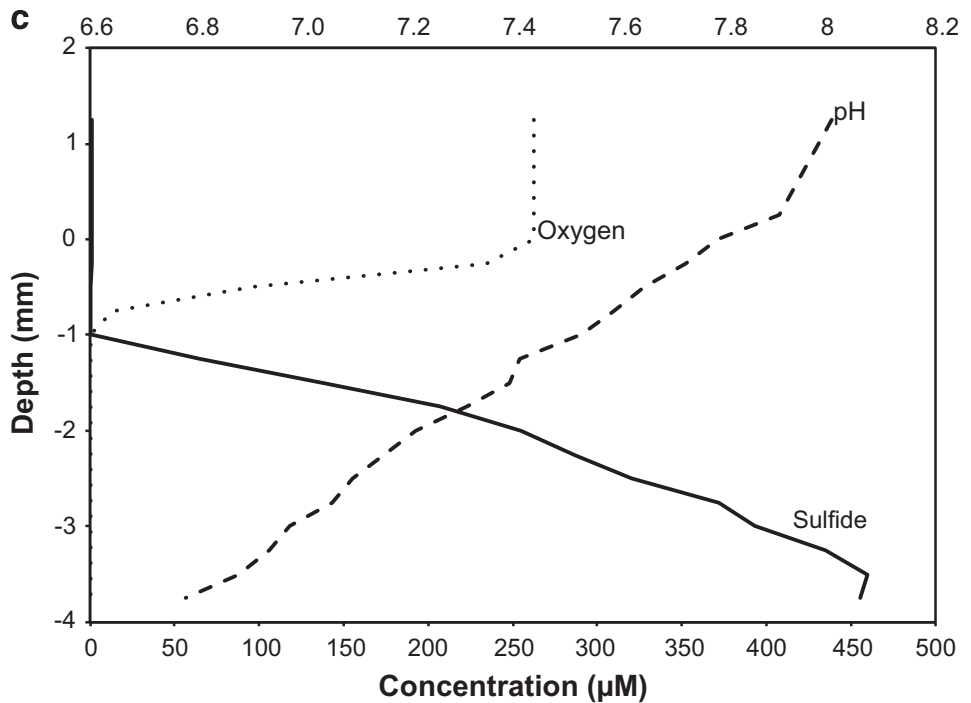

Figure 5 Photography of the 40-day-old wood mat (a) used to do the elemental mapping of sulfur (b) and the microprofiles of pH, sulfide and oxygen (c). Elemental mapping at two different scales (b) revealed the areas of sulfur accumulation (high density of detector counts represented by a high density of red pixels).

with a white biofilm (Figure 5a) after 40 days. This mat had exactly the same general aspect as those observed during the first microbial experiment. The mapping of sulfur accumulation on the mat surface revealed an inhomogeneous distribution of sulfur on the mat surface with some areas enriched in sulfur (in red) and some depleted (Figure 5b). Within the mat the $\mathrm{pH}$ decreased from $8(1 \mathrm{~mm}$ above the surface) to 6.8 on the wood surface. Oxygen decreased from $262 \mu \mathrm{M}$ at the mat surface to $0 \mu \mathrm{M}$ at $1.25 \mathrm{~mm}$ below the mat surface. Sulfide was detected $1.50 \mathrm{~mm}$ below the mat surface and increased steadily up to $455 \mu \mathrm{M}$ at $3.75 \mathrm{~mm}$ below the mat surface (Figure 5c).

\section{Discussion}

Our experiment revealed the identity and function of the microbes constituting wood fall-associated mats and gave the first opportunity to study the dynamics of this unknown ecosystem. We could thus demonstrate an ecological succession in the bacterial community assembly and potential metabolisms, and establish the chemosynthetic nature of woodcolonizing mats.

Ecological succession during epixylic mat formation The first bacterial community that reproducibly colonized wood falls after ca. 1 month of immersion was mainly composed of Epsilonproteobacteria. These pioneer communities were dominated by an unknown OTU distantly related to the Arcobacter genus (Otu2). Another dominant Epsilonproteobacteria (Otu8) was closely related to Arcobacter nitrofigilis (Pati et al., 2010), which is a chemoorganotrophic bacteria that use nitrate as electron acceptor. The white appearance of the biofilm may indicate the capacity of Otu8 to produce elemental sulfur from hydrogen sulfide oxidation as observed for Candidatus Arcobacter sulfidicus (Wirsen et al., 2002; Sievert et al., 2007). Hydrogen sulfide or organic compounds (used by the $A$. nitrofigilisrelated Otu8) were all shown to be breakdown products of wood degradation (Leschine, 1995; 
Yücel et al., 2013; Kalenitchenko et al., 2015). During this first stage of mat formation, the Epsilonproteobacteria shared their habitat with seven Gammaproteobacteria OTUs related to the aerobic genera Thalassolituus and Marinomonas (Yakimov et al., 2004; Prabagaran et al., 2005). Our results, together with observations made on a sulfideoxidizing community in the Black sea (Jørgensen et al., 1991), suggest that this first, potentially sulfide-oxidizing mat community, has an important role in protecting the wood fall surrounding environment against hydrogen sulfide produced during the wood decay.

After ca. 45 days, the bacterial communities started to change with an increase of the relative proportion of Deltaproteobacteria sequences that was inversely correlated with a significant decrease of Epsilonproteobacteria sequences. Deltaproteobacteria were dominated by sequences related to the Desulfovibrio genera (Otu3) previously found associated to wood falls (Khelaifia et al., 2011; Kalenitchenko et al., 2015). This genera of sulfatereducing bacteria is strictly anaerobic, uses fermentation end products as a carbon source, respires sulfate and thus produces hydrogen sulfide (Pradel et al., 2013). The mat thickness increase with time may be linked to the displacement of the oxygensulfide interface from the wood surface toward the seawater as observed on other Epsilonproteobacteria mats (Wirsen et al., 2002; Sievert et al., 2007). This displacement limits the penetration of potential electron acceptors like oxygen and nitrate, thus promoting the development of anaerobic and nitrate depleted niches (Van Houten et al., 1994; Okabe et al., 2005) on the wood side of the mat as shown by the microsensor measurements taken in our second experiment (Figure 5c). These new ecological niches presented ideal conditions for the development of sulfate-reducing bacteria but were probably not favorable for chemoorganotrophic bacteria, like A. nitrofigilis (Otu8), which disappeared as the mat grew.

Interestingly, the mat showed a unique feature at this stage since the community was composed half of sulfate-reducing bacteria and half of an Arcobacterrelated OTUs. The presence of sulfate-reducing bacteria maintaining the production of hydrogen sulfide could provide an ideal niche for potential sulfur-oxidizing Arcobacter (like unknown Otu1 or Otu2), probably located on the biofilm upper layers, where oxygen or nitrate from the seawater and hydrogen sulfide from the wood co-occur. Such a co-occurrence of sulfate reducers and sulfur oxidizers within the same microbial mat has not been previously documented in other chemosynthetic ecosystems (whale falls, cold seeps or hydrothermal vents) but such consortia are known to occur in symbiosis with oligochaete worms (Blazejak et al., 2005).

At the end of our experiment, the biofilm was thicker. We can hypothesize that even if the mat grew, the niche suitable for bacteria dependent on electron acceptors like oxygen and nitrate did not increase, as the penetration of electron acceptors had decreased (Santegoeds et al., 1998; Figure 6). However, other electron acceptors like sulfate ions are not used in the upper part of the mats and could penetrate deeper and reach the wood where they are reduced (Yücel et al., 2013). The penetration of sulfate maintained the sulfate-reducing bacteria ecological niche, which probably occupied all the space between the wood surface and the hydrogen sulfide-oxidizing layer, resulting in an increase in the proportion of sequences related to the Desulfovibrio genera.

The increasing distance between the mat-water interface and the wood surface probably resulted in a selection of bacteria that did not use the organic carbon from the wood. These bacteria, like the chemolithoautotroph Candidatus A. sulfidicusrelated OTU (Otu7), would prefer to fix the inorganic carbon present in seawater. Arcobacter-related OTUs may be responsible for the white coloration observed on our mat because they do an incomplete oxidation of sulfide to elemental sulfur, which produces white sulfur filaments visible to the naked eye (Wirsen et al., 2002; Sievert et al., 2007). In addition to the visual observation of this elemental sulfur, we detected Deferribacteres OTUs that might utilize this

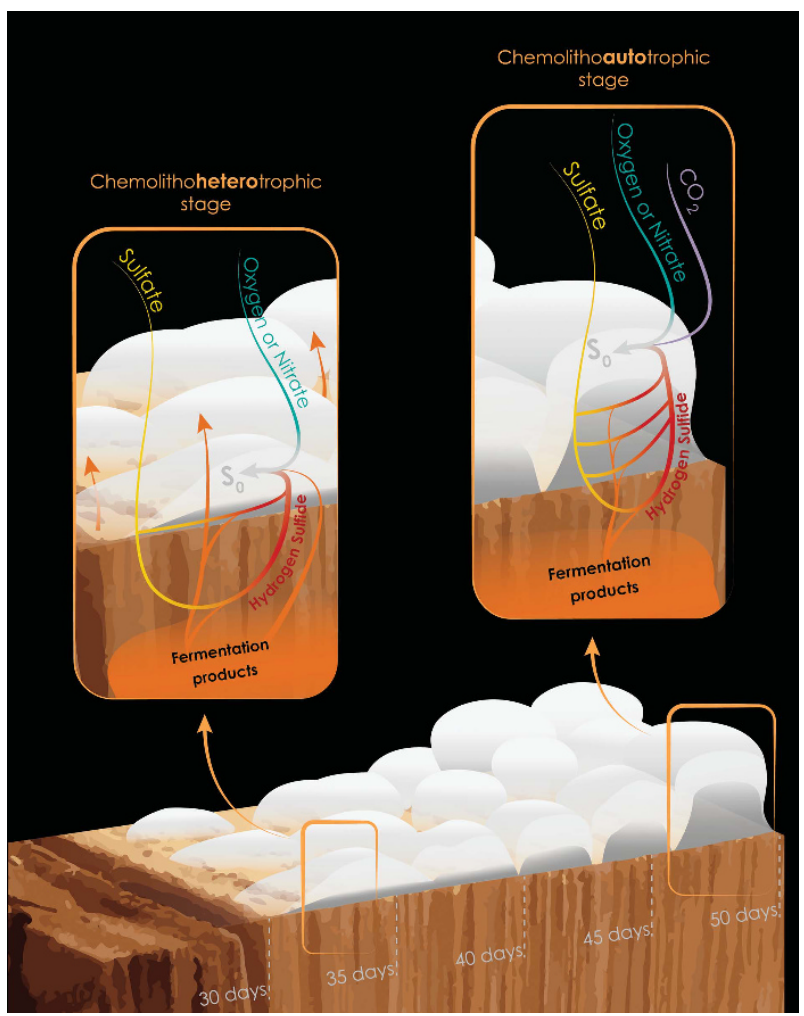

Figure 6 Schematic illustration of the ecological succession within the epixylic mat. The two zoomed areas portray the potential metabolisms detected in the mat. The size of the area representing sulfate-reducing bacteria (gray area) and sulfideoxidizing bacteria (white area) is proportional to the number of $16 \mathrm{~S}$ rRNA sequences detected at the different time points. 
elemental sulfur as a terminal electron acceptor (Garrity and Holt, 2001) giving another clue about the sulfur filament formation. Furthermore our second chemical analysis experiment revealed an inhomogeneous distribution of sulfur on the mat surface that confirmed the capacity of this system to accumulate sulfur. These community changes also impacted the Gammaproteobacteria class that evolved from seven aerobic OTUs after 32 days to only one unknown OTU probably more adapted to anoxia, at the end of the experiment. This possible succession observed with sequence data could be validated in the future with further experiments involving the localization of specific OTUs using FISH probes.

Metabolic potential of the epixylic mat

Using a metagenomic approach we were able to detect the presence of genes coding for key enzymes involved in the potential metabolisms of the bacterial groups cited above. Our results indicate that from the first stage of colonization to the end, the microbial community had all the potential functional genes needed for the growth and maintenance of the epixylic mat. The presence of napA, napB and nar genes validated the finding that the bacterial community had the potential to produce the nitrate reductase protein (Smith et al., 2007) and thus confirmed the capacity of the microbial pool to use nitrate as an electron acceptor.

Our $16 \mathrm{~S}$ rRNA data indicated that the upper mat layer might have recruited some chemolithoautotrophic bacteria. This was confirmed by the increase of the relative sequence abundance of rTCA cyclerelated genes, including the fumarate reductase ( $f r d A$ ), the 2-oxoglutarate ferredoxin oxidoreductase (oor) and the acetyl-CoA decarboxylase (acs), involved in the $\mathrm{CO}_{2}$ fixation pathway. However, the ATP citrate marker gene ( $A C L Y$ ), the key enzyme of the rTCA cycle, was not found in the beginning of the colonization indicating the microbial community incapacity to run the rTCA cycle during the first development stage. The rTCA pathway is widely used by Epsilonproteobacteria (Campbell and Cary, 2004; Hügler et al., 2010) to fix carbon dioxide in anaerobic or microanaerobic conditions, which confirms that our community has acquired the potential to fix inorganic carbon between 32 and 45 days of immersion. The fact that we observed a decrease of the number of sequences related to the Bacteroidetes starch sequestration system further corroborates the hypothesis that the upper layer of the microbial mat became less dependent on the wood carbon with time.

The detection of Desulfovibrio-related sulfate reductase ( $d s r)$ and adenylylsulfate reductase (apr) genes evidenced the community's potential for sulfate reduction. The proportion of $d s r$ and $a p r$ genes increased at the end of the experiment supporting the hypothesis of the presence of sulfate-reducing Desulfovibrio-related bacteria (Otu3), which quickly dominated the wood mat community. The common presence of Desulfovibrio in wood falls (Bienhold et al., 2013; Fagervold et al., 2013; Pradel et al., 2013; Kalenitchenko et al., 2015) and measures of hydrogen sulfide pulses on wood surfaces after 1 month (Yücel et al., 2013; Kalenitchenko et al., 2015) suggests the importance of this genera for the production of hydrogen sulfide from wood falls. In addition, the bacterial community's potential to use hydrogen sulfide as electron donor was confirmed by the detection of the sulfur oxidation protein coding gene $\operatorname{sox} B$. This finding supports the theory that the unknown Otu2, most closely related to Arcobacter, detected at the beginning of the experiment was able to use hydrogen sulfide as an electron donor and may be responsible for the white elemental sulfur accumulation in the mat. However, there is no sign that the early colonizers can fix inorganic carbon through the rTCA cycle. We therefore hypothesize that the first dominant OTU used chemolithoheterotrophy, which may give a competitive advantage over chemolithoautotrophy in high organic carbon environments (Sorokin, 2003; Moran et al., 2004). After 45 days, the bacterial mat conditions probably allowed the establishment of bacteria with the potential for chemolithoautotrophy, which use carbon dioxide as a carbon source and inorganic compounds (hydrogen sulfur) as electron donors. We conclude that after the first stages of colonization, the biofilm had all the genetic potential to set up a chemosynthetic ecosystem.

\section{Conclusion}

Here we present a first description of the diversity and potential metabolisms of the bacterial communities forming mats on wood falls in the sea. First, an Arcobacter-related community dominated chemoorganotrophic mats developed on hydrogen sulfide and organic carbon from wood fermentation (Figure 6). Second, the thickening of the mat created new ecological niches for the co-occurrence of sulfideoxidizing and sulfate-reducing bacteria. Finally, at a later stage, we hypothesize the selection of chemolithoautotrophic Arcobacter, instead of chemolithoheterotrophic Arcobacter, caused by the preferential utilization of organic carbon from fermentation products by the growing population of sulfate-reducing bacteria. Our work also demonstrates the utility to develop experimental incubation in the laboratory to study deep-sea chemosynthetic mats. The easy access to samples allows short-term temporal studies for a precise description of mat formation.

\section{Conflict of Interest}

The authors declare no conflict of interest. 


\section{Acknowledgements}

The present work was supported by the Agence Nationale de la Recherche (ANR) project MICADO (ANR-11JSV7-Q23-00301). We acknowledge Erwan Peru for his help during the utilization of microsensors and we thank the BIO2MAR platform (http://bio2mar.obs-banyuls.fr) for providing technical support and access to instrumentation. We are also grateful to Julie Rius and Benjamin Falgas from the 'Biodiversarium' in Banyuls sur Mer for their kind and precious help in providing pinewood and Yannick Banuls from the laboratory carpentry for precisely cutting the wood logs.

\section{References}

Alain K, Zbinden M, Le Bris N, Lesongeur F, Quérellou J, Gaill F et al. (2004). Early steps in microbial colonization processes at deep-sea hydrothermal vents. Environ Microbiol 6: 227-241.

Amann RI, Binder BJ, Olson RJ, Chisholm SW, Devereux R, Stahl DA. (1990). Combination of 16S rRNA-targeted oligonucleotide probes with flow cytometry for analyzing mixed microbial populations. Appl Environ Microb 56: 1919-1925.

Ben-Dov E, Siboni N, Shapiro OH, Arotsker L, Kushmaro A. (2011). Substitution by inosine at the $3^{\prime}$-ultimate and penultimate positions of $16 \mathrm{~S}$ rRNA gene universal primers. Microb Ecol 61: 1-6.

Bienhold C, Pop Ristova P, Wenzhöfer F, Dittmar T, Boetius A. (2013). How deep-sea wood falls sustain chemosynthetic life. Plos One 8: e53590.

Blair NE, Aller RC. (2012). The fate of terrestrial organic carbon in the marine environment. Annu Rev Marine Sci 4: 401-423.

Blazejak A, Erséus C, Amann R, Dubilier N. (2005). Coexistence of bacterial sulfide oxidizers, sulfate reducers, and spirochetes in a gutless worm (Oligochaeta) from the Peru margin. Appl Environ Microb 71: 1553-1561.

Camacho C, Coulouris G, Avagyan V, Ma N, Papadopoulos J, Bealer K et al. (2009). BLAST+: architecture and applications. BMC Bioinformatics 10: 421.

Campbell BJ, Cary SC. (2004). Abundance of reverse tricarboxylic acid cycle genes in free-living microorganisms at deep-sea hydrothermal vents. Appl Environ Microb 70: 6282-6289.

Campbell BJ, Engel AS, Porter ML, Takai K. (2006). The versatile I[epsi]|-proteobacteria: key players in sulphidic habitats. Nat Rev Micro 4: 458-468.

Cox MP, Peterson DA, Biggs PJ. (2010). SolexaQA: at-a-glance quality assessment of Illumina second-generation sequencing data. BMC Bioinformatics 11: 485.

Duperron S, Laurent MC, Gaill F, Gros O. (2008). Sulphuroxidizing extracellular bacteria in the gills of Mytilidae associated with wood falls. FEMS Microbiol Ecol 63 : 338-349.

Edgar RC, Haas BJ, Clemente JC, Quince C, Knight R. (2011). UCHIME improves sensitivity and speed of chimera detection. Bioinformatics 27: 2194-2200.

Fagervold SK, Bessette S, Romano C, Martín D, Plyuscheva M, Le Bris $\mathrm{N}$ et al. (2013). Microbial communities associated with the degradation of oak wood in the Blanes submarine canyon and its adjacent open slope (NW Mediterranean). Prog Oceanogr 118: 137-143.

Fagervold SK, Romano C, Kalenitchenko, Borowski C, Nunes-Jorge A, Martin D et al. (2014). Microbial communities in sunken wood are structured by wood-boring bivalves and location in a submarine canyon. Plos One 9: e96248.

Felden J. (2009). Biogeochemical processes associated with mud volcanism on the Nile Deep Sea580 Fan - the Amon mud volcano. In: Methane Fluxes and Associated Biogeochemical Processes in Cold581 Seep Ecosystems. Jacobs University Bremen/Max Planck Institute for Marine Microbiology: Bremen, Germany, pp 51-77.

Flemming H-C, Wingender J. (2010). The biofilm matrix. Nat Rev Microbiol 8: 623-633.

Flint HJ, Bayer EA, Rincon MT, Lamed R, White BA. (2008). Polysaccharide utilization by gut bacteria: potential for new insights from genomic analysis. Nat Rev Microbiol 6: 121-131.

Garrity GM, Holt JG. (2001). Phylum BIX. Deferribacteres phy. nov. In: Boone DR, Castenholz RW (eds), Bergeys Manual of Systematic Bacteriology, 2nd edn, Vol 1. Springer-Verlag: New York, NY, USA, pp 465-471.

Gentz T, Schlüter M. (2012). Underwater cryotrapmembrane inlet system (CT-MIS) for improved in situ analysis of gases. Limnol Oceanogr-Meth 55: 2366-2380.

Girnth AC, Grünke S, Lichtschlag A, Felden J, Knittel K, Wenzhöfer F et al. (2011). A novel, mat-forming thiomargarita population associated with a sulfidic fluid flow from a deep-sea mud volcano. Environ Microbiol 13: 495-505.

Golladay SW, Sinsabaugh RL. (1991). Biofilm development on leaf and wood surfaces in a boreal river. Freshwater Biol 25: 437-450.

Gomez-Alvarez V, Teal TK, Schmidt TM. (2009). Systematic artifacts in metagenomes from complex microbial communities. ISME J 3: 1314-1317.

Grünke S, Felden J, Lichtschlag A, Girnth AC, De Beer D, Wenzhöfer F et al. (2011). Niche differentiation among mat-forming, sulfide-oxidizing bacteria at cold seeps of the Nile Deep Sea Fan (Eastern Mediterranean Sea). Geobiology 9: 330-348.

Heijs SK, Damsté JSS, Forney LJ. (2005). Characterization of a deep-sea microbial mat from an active cold seep at the Milano mud volcano in the Eastern Mediterranean Sea. FEMS Microbiol Ecol 54: 47-56.

Hügler M, Gärtner A, Imhoff JF. (2010). Functional genes as markers for sulfur cycling and $\mathrm{CO} 2$ fixation in microbial communities of hydrothermal vents of the Logatchev field. FEMS Microbiol Ecol 73: 526-537.

Hügler M, Sievert SM. (2011). Beyond the calvin cycle: autotrophic carbon fixation in the ocean. Annu Rev Marine Sci 3: 261-289.

Jørgensen BB, Fossing H, Wirsen CO, Jannasch HW. (1991). Sulfide oxidation in the anoxic Black Sea chemocline. Deep Sea Res 38: S1083-S1103.

Kalenitchenko Fagervold SK, Pruski AM, Vétion G, Yücel M, Le Bris $\mathrm{N}$ et al. (2015). Temporal and spatial constraints on community assembly during microbial colonization of wood in seawater. ISME J 9: 2657-2670.

Kanehisa M. (2002). The KEGG database. Novartis Found Symp 247: 91-101.

Khelaifia S, Fardeau M-L, Pradel N, Aussignargues C, Garel M, Tamburini C et al. (2011). Desulfovibrio piezophilus sp. nov., a piezophilic, sulfate-reducing bacterium isolated from wood falls in the Mediterranean Sea. Int J Syst Evol Micr 61: 2706-2711.

Kozich JJ, Westcott SL, Baxter NT, Highlander SK, Schloss PD. (2013). Development of a dual-index sequencing strategy and curation pipeline for analyzing amplicon sequence data on the MiSeq Illumina sequencing platform. Appl Environ Microb 79: 5112-5120. 
Laurent MCZ, Le Bris N, Gaill F, Gros O. (2013). Dynamics of wood fall colonization in relation to sulfide concentration in a mangrove swamp. Mar Environ Res 87-88: 85-95.

Lauro FM, DeMaere MZ, Yau S, Brown MV, Ng C, Wilkins D et al. (2011). An integrative study of a meromictic lake ecosystem in Antarctica. ISME J 5: 879-895.

Le Bris N, Govenar B, Le Gall C, Fisher CR. (2006) Variability of physico-chemical conditions in $9^{\circ} 50^{\prime} \mathrm{N}$ EPR diffuse flow vent habitats. Mar Chem 98: 167-182.

Leschine SB. (1995). Cellulose degradation in anaerobic environments. Annu Rev Microbiol 49: 399-426.

Lin X, Wakeham SG, Putnam IF, Astor YM, Scranton MI, Chistoserdov AY et al. (2006). Comparison of vertical distributions of prokaryotic assemblages in the anoxic Cariaco Basin and Black Sea by use of fluorescence in situ hybridization. Appl Environ Microb 72: 2679-2690.

Llorens-Marès T, Yooseph S, Goll J, Hoffman J, Vila-Costa M, Borrego CM et al. (2015). Connecting biodiversity and potential functional role in modern euxinic environments by microbial metagenomics. ISME J 9: 1648-1661.

López-García P, Duperron S, Philippot P, Foriel J, Susini J, Moreira D. (2003). Bacterial diversity in hydrothermal sediment and epsilonproteobacterial dominance in experimental microcolonizers at the Mid-Atlantic Ridge. Environ Microbiol 5: 961-976.

Manz W, Amann R, Ludwig W, Wagner M, Schleifer K-H. (1992). Phylogenetic oligodeoxynucleotide probes for the major subclasses of proteobacteria: problems and solutions. Syst Appl Microbiol 15: 593-600.

Meyer F, Paarmann D, D'Souza M, Olson R, Glass EM, Kubal M et al. (2008). The metagenomics RAST server a public resource for the automatic phylogenetic and functional analysis of metagenomes. BMC Bioinformatics 9: 386.

Moran MA, Buchan A, González JM, Heidelberg JF, Whitman WB, Kiene RP et al. (2004). Genome sequence of Silicibacter pomeroyi reveals adaptations to the marine environment. Nature 432: 910-913.

Moussard H, Corre E, Cambon Bonavita M-A, Fouquet Y, Jeanthon C. (2006). Novel uncultured Epsilonproteobacteria dominate a filamentous sulphur mat from the 13 degrees N hydrothermal vent field, East Pacific Rise. FEMS Microbiol Ecol 58: 449-463.

Okabe S, Ito T, Sugita K, Satoh H. (2005). Succession of internal sulfur cycles and sulfur-oxidizing bacterial communities in microaerophilic wastewater biofilms. Appl Environ Microb 71: 2520-2529.

Pati A, Gronow S, Lapidus A, Copeland A, Glavina Del Rio T, Nolan M et al. (2010). Complete genome sequence of Arcobacter nitrofigilis type strain (CIT). Stand Genomic Sci 2: 300-308.

Pernthaler A, Pernthaler J, Amann R. (2002). Fluorescence in situ hybridization and catalyzed reporter deposition for the identification of marine bacteria. Appl Environ Microb 68: 3094-3101.

Prabagaran SR, Suresh K, Manorama R, Delille D, Shivaji S. (2005). Marinomonas ushuaiensis sp. nov., isolated from coastal sea water in Ushuaia, Argentina, subAntarctica. Int J Syst Evol Micr 55: 309-313.

Pradel N, Ji B, Gimenez G, Talla E, Lenoble P, Garel M et al. (2013). Thefirst genomic and proteomic characterization of a deep-sea sulfate reducer: insights into the piezophilic lifestyle of Desulfovibrio piezophilus. Plos One 8: e55130.

Pruesse E, Quast C, Knittel K, Fuchs BM, Ludwig W, Peplies J et al. (2007). SILVA: a comprehensive online resource for quality checked and aligned ribosomal RNA sequence data compatible with ARB. Nucleic Acids Res 35: 7188-7196.

Purchon RD. (1941). On the biology and relationships of the Lamellibranch Xylophaga Dorsalis (Turton). J Mar Biol Assoc UK 25: 1-39.

Rho M, Tang H, Ye Y. (2010). FragGeneScan: predicting genes in short and error-prone reads. Nucleic Acids Res 38: e191-e191.

Rickard D, Luther GW. (2007). Chemistry of iron sulfides. Chem Rev 107: 514-562.

Samadi S, Corbari L, Lorion J, Hourdez S, Haga T, Dupont J et al. (2010). Biodiversity of deep-sea organisms associated with sunken-wood or other organic remains sampled in the tropical Indo-Pacific. Cah Biol Mar 51: 459-466.

Santegoeds CM, Ferdelman TG, Muyzer G, de Beer D. (1998). Structural and functional dynamics of sulfate reducing populations in bacterial biofilms. Appl Environ Microb 64: 3731-3739.

Sievert SM, Wieringa EBA, Wirsen CO, Taylor CD. (2007). Growth and mechanism of filamentous-sulfur formation by Candidatus Arcobacter sulfidicus in opposing oxygen-sulfide gradients. Environ Microbiol 9: 271276.

Sjostrom E. (1993). Wood Chemistry. Academic Press: San Diego, CA, USA.

Smith CJ, Nedwell DB, Dong LF, Osborn AM. (2007). Diversity and abundance of nitrate reductase genes (narG and napA), nitrite reductase genes (nirS and nrfA), and their transcripts in estuarine sediments. Appl Environ Microb 73: 3612-3622.

Sorokin DY. (2003). Oxidation of inorganic sulfur compounds by obligately organotrophic bacteria. Microbiology 72: 641-653.

Takai K, Campbell BJ, Cary SC, Suzuki M, Oida H, Nunoura $\mathrm{T}$ et al. (2005). Enzymatic and genetic characterization of carbon and energy metabolisms by deep-sea hydrothermal chemolithoautotrophic isolates of Epsilonproteobacteria. Appl Environ Microb 71: 7310-7320.

Tank JL, Webster JR. (1998). Interaction of substrate and nutrient availability on wood biofilm processes in streams. Ecology 79: 2168-2179.

Tank JL, Winterbourn MJ. (1995). Biofilm development and invertebrate colonization of wood in four New Zealand streams of contrasting pH. Freshwater Biol 34: 303-315.

Taylor C, Wirsen C, Gaill F. (1999). Rapid microbial production of filamentous sulfur mats at hydrothermal vents. Appl Environ Microb 65: 2253-2255.

Van Dover CL, Fry B. (1989). Stable isotopic compositions of hydrothermal vent organisms. Mar Biol 102: 257-263.

Van Houten RT, Pol LW, Lettinga G. (1994). Biological sulphate reduction using gas-lift reactors fed with hydrogen and carbon dioxide as energy and carbon source. Biotechnol Bioeng 44: 586-594.

Vandieken V. (2006). Desulfovibrio frigidus sp. nov. and Desulfovibrio ferrireducens sp. nov., psychrotolerant bacteria isolated from Arctic fjord sediments (Svalbard) with the ability to reduce Fe(III). Int J Syst Evol Micr 56: 681-685.

Voight JR. (2015). Xylotrophic bivalves: aspects of their biology and the impacts of humans. J Mollus Stud 81: 175-186.

Wirsen CO, Sievert SM, Cavanaugh CM, Molyneaux SJ, Ahmad A, Taylor LT et al. (2002). Characterization of 
an autotrophic sulfide-oxidizing marine Arcobacter sp. that produces filamentous sulfur. Appl Environ Microb 68: 316-325.

Yakimov MM, Giuliano L, Denaro R, Crisafi E, Chernikova TN, Abraham W-R et al. (2004). Thalassolituus oleivorans gen. nov., sp. nov., a novel marine bacterium that obligately utilizes hydrocarbons. Int $J$ Syst Evol Micr 54: 141-148.

Yücel M, Galand PE, Fagervold SK, Contreira-Pereira L, Le Bris N. (2013). Sulfide production and consumption in degrading wood in the marine environment. Chemosphere 90: 403-409.

Supplementary Information accompanies this paper on The ISME Journal website (http://www.nature.com/ismej) 